\title{
Peertechz
}
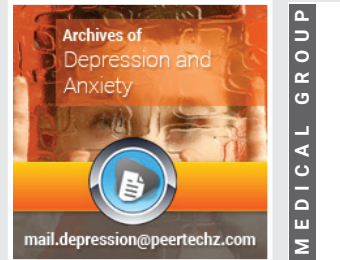

Research Article

\section{Prevalence of perceived} \section{depression and anxiety among} hypertensives attending imo specialist hospital owerri,

\section{Nigeria}

Chikere Ifeanyi Casmir Ebirim ${ }^{1 *}$, Ugonma Winnie Dozie', Somtochukwu Mercy Orji', Angela Juliet Uka-Okali², Uchenna Launa Iwumune ${ }^{3}$, Queen KenechukwuDozie', Leo clinton Chukwu ${ }^{4}$, Ekundayo Babajide Otuyelu ${ }^{5}$, Chidiebere Peter Echieh ${ }^{6}$, Uchenna Ewelike ${ }^{7}$, Emmanuel Adeyemi Odumeru $^{8}$, Alvan Ifeanyi Okene ${ }^{9}$, Uchenna Francis Agu ${ }^{10}$ and Maureen Maduagwu'11

\footnotetext{
${ }^{1}$ Department of Public Health, Federal University of Technology Owerri, Nigeria

${ }^{2}$ Federal Medical Centre, Umuahia, Abia State, Nigeria

${ }^{3}$ Rimma Hospital, No. 4 College road, Umudagu Mbieri, Owerri, Nigeria

${ }^{4}$ Department of Pharmacology, Chukwuemeka Odumegwu Ojukwu University, Awka Camps, Nigeria ${ }^{5}$ Edi International Hospital, 1 Coronation Drive, off Aideyan Avenue GRA, Benin City, Edo State, Nigeria ${ }^{6}$ Department of Surgery, University of Calabar/University of Calabar Teaching Hospital, Calabar Nigeria ${ }^{7}$ National Health Insurance Scheme, Abuja, Nigeria ${ }^{8}$ Department of Medical Imaging Science, College of Medicine and Health Science, University of Rwanda, Remera, Kigali Campus, Rwanda

'Universal Basic Education (UBE), Ministry of Education, Port Harcourt, Rivers State, Nigeria ${ }^{10}$ Department of Human Physiology, College of Medicine, University of Nigeria Enugu Campus, Enugu State, Nigeria

${ }^{11}$ Health Services Department, Rivers State University, Port Harcourt, Nigeria
}

\section{Abstract}

Background: Depression is a burdensome disease of global importance, and although prevalent, it is mostly undiagnosed in patients with hypertension. Anxiety is another significant factor associated with increased Blood Pressure and is an independent predictor of future hypertension. The aim of this study was to determine the prevalence of depression and anxiety among hypertensive's attending Imo Specialist Hospital Owerri, Nigeria.

Citation: Casmir Ebirim Cl, Dozie UW, Orji SM, Uka-Okali AJ, Iwumune UL, et al. (2020) Prevalence of perceived depression and anxiety among hypertensives attending imo specialist hospital owerri, Nigeria. Arch Depress Anxiety 6(2): 045-049. DOI: https://dx.doi.org/10.17352/2455-5460.000051 
Methods: A hospital based cross sectional study was undertaken, utilizing systematic random sampling method in the recruitment of 334 respondents. Depression and anxiety was determined using a standard tool known as depression, anxiety, and stress scale-21 (DASS-21). The questionnaire was administered to the respondents by the researcher after an informed consent was obtained. Data were analyzed using SPSS version 21

Results: A total of 334 respondents were recruited for the study comprising 190 (56.9\%) females and 144 (43.1\%) males. The Overall prevalence of depression and anxiety among the hypertensive patients was $77.8 \%$. The result indicated that among the hypertensive's, 242 (72.5\%) had both conditions of depressed and anxious, 74 (22.2\%) were neither depressed nor anxious, 14 (4.1\%) were anxious but not depressed while 4 (1.2\%) were depressed but not anxious.

Conclusion: A combination of hypertensive medications with psychotherapy and antidepressants can definitely help prevent severe attacks of High Blood Pressure. Hence, the study recommends the need for psychiatric evaluation, counseling, and support services for hypertensive patients as an important component for the management of hypertension especially at advanced stage.

\section{Background to the study}

Hypertension is a chronic disease with high morbidity and mortality rate. The etiology of hypertension is multi-factorial, which results from the combined influence of genetic and environmental factors. It predisposes to coronary heart disease and cardiac dysfunction and has deleterious neurological effects on retina, central nervous system, and kidneys [1]. The burden of depression and anxiety among hypertensive patients is rapidly increasing. A hypertensive patient with depression and anxiety will experience a change in sleep patterns and excessive energy loss [2]. People with this condition are not efficient in the work place thereby reducing the country's labour force. It may also be difficult for patients with this condition to attend social gatherings. The presence of this condition increases the financial burden of the patient as he attempts to improve his health. It also increases the job description of the patient's care giver. Hypertensive patients suffering from depression and anxiety are at a higher risk to develop cardiovascular disease [3]. All medical professionals should take extra caution to prevent lethal complication by treating hypertension, depression and anxiety properly. Hypertensive patients experience many profound emotions which increase their risk for the development of mental health disorders, particularly anxiety and depression [4].

Depression is a burdensome disease of global importance, and although prevalent, it is mostly undiagnosed in patients with hypertension. The research evidence suggests that anxiety is another significant cause of increased BP and is an independent predictor of future hypertension [5].

Depressive symptoms and syndromes are common in the medically ill, although they are frequently unrecognized and untreated. Hypertension is significantly associated with symptoms of depression [6].

One of the known factors associated with poor compliance with antihypertensive medication was depression and scientific studies have examined the relation between them. However it has also been proposed that hypertension itself is a risk factor for depression. In Malaysia, neurotic depression (3.31\%) is the most common psychiatric diagnosis and the prevalence of emotional disorders is $15.2 \%$. This indicates clearly that hypertensive patients who are suffering from depressive illness are at a higher risk to develop cardiovascular disease. All medical professionals should take extra caution to prevent lethal complication by treating hypertension and depression properly [3].
In one study on normotensive and mildly hypertensive patients, the perception of being hypertensive was associated with greater anxiety during clinic BP measurement [5]. Anxiety disorder is amongst the most common psychiatric disorders all over the world. Emerging evidence suggests that anxiety and the anxiety disorders, which have received relatively less attention in many patients, have co-morbid anxiety symptoms that are associated with increased severity of psychiatric illness, additive functional impairment and medical costs and also amplify symptoms of some medical illnesses and appear to worsen clinical outcomes. However, there is a remarkable lack of data from rigorously designed clinical trials to guide treatment decisions in patients with common medical illness [7]

Anxiety disorders are common and costly in older adults and the detection and diagnosis of anxiety disorders in late life is complicated by medical co-morbidity, cognitive decline, and changes in life circumstances that do not face younger age groups. Furthermore, the expression and report of anxiety symptoms may differ with age. For these reasons, anxiety disorders in late life may be even more likely to be under diagnosed than in younger age groups [8]. Patients with anxiety exhibit a higher likelihood of medication nonadherence on hypertension treatment and they may limit the feature of treatment option, worsen the prognosis of patients increase death rate from the disease or the ability to enjoy life [9].

Research evidence suggests that anxiety is another significant cause of increased BP and is an independent predictor of future hypertension. Similarly, stress is known to be significantly correlated with hypertension and causes many cardiac problems. Natural reaction of the cardiovascular response to stress is the increase in heart rate [5].

\section{Methodology}

Hospital based cross-sectional study was conducted at Imo Specialist Hospital, Owerri, Nigeria. Imo Specialist Hospital, Owerri is a public general hospital located in Owerri West Local Government Area, Imo State, Nigeria. Umuguma stretches from the Northern part at the roundabout on Sam Mbakwe Avenue by Dream-Land Hotel, through the Coca-Cola Factory off Irete Road on the East, to the Federal Secretariat Complex on Port Harcourt Road to the West and through Port Harcourt expressway including all the Housing Estates - World Bank, Federal and Imo State Housing estates. It borders Owerri at the

Citation: Casmir Ebirim Cl, Dozie UW, Orji SM, Uka-Okali AJ, Iwumune UL, et al. (2020) Prevalence of perceived depression and anxiety among hypertensives attending imo specialist hospital owerri, Nigeria. Arch Depress Anxiety 6(2): 045-049. DOI: https://dx.doi.org/10.17352/2455-5460.000051 
north, Nekede at the west, Irete and Okuku on the east and Avu at the south (Wikipedia, 2017). The study population consisted of all adult hypertensive patients both new and old who came for check up at Imo Specialist Hospital. Those hypertensive patients who were critically ill were excluded from the study because they were not physically strong enough to answer research questions.

A systematic sampling technique was used. On the average, the hospital attends to 15 hypertensive patients per day. This gives a total of 1,350 patients for the three months study duration. The sampling fraction was determined by dividing the total population of 1,350 by 334 samples. This gives a sample fraction of $1350 / 334=4.04$. This was achieved by selecting the first patient at random and recruiting every four patients that comes on a daily basis for the three months study duration. Three to four patients were recruited per day following this method.

Data were collected using pretested interviewer administered Questionnaire. Questionnaire was administered to the respondents after obtaining their consent and all necessary explanation given to the respondents. Permission to conduct the study was obtained from the Chief Medical Director. During the data collection, Respondents were assured of confidentiality of information. The questionnaire was made up of section A and B. Section A addressed socio-demographic features of the respondent. Section B was a standardized validated set of questions on depression, anxiety, and stress scale-21 (DASS-21). The questionnaire was administered to the respondents by the researcher after an informed consent was obtained. The literate respondents were allowed to fill the questionnaire themselves but for non-literate respondents, the questions were asked in local language and their responses were filled by the researcher. Each questionnaire takes about46 minutes time to be completed.

Data collected was collated and inputted into statistical package for social sciences version 21.0. The analyzed data were presented using frequency distribution tables with percentage, and charts.

\section{Result}

\section{Socio-demographic characteristics of the participants}

The socio-demographic characteristics of hypertensive patients attending Imo Specialist Hospital, Owerri, Nigeria is presented below. A total of 334 respondents were recruited for the study comprising 190 (56.9\%) females and $144(43.1 \%)$ males. The respondents were within the age range of $20-29$ years $(6.0 \%), 30-39$ years $(14.4 \%), 40-49$ years $(11.4 \%), 50$ - 59 years $75(22.5 \%), 60-69$ years $91(27.2 \%)$ and 70 years and above $(18.6 \%)$. Marital Status of respondents showed that $27(8.1 \%)$ were single, $238(71.3 \%)$ were married, while 69 $(20.7 \%)$ were widowed. The education levels of respondents indicated that $33(9.9 \%)$, primary $44(14.2 \%)$ had no formal education, $114(34.1 \%)$ attained secondary level of education and $143(42.8 \%)$ had tertiary education. Monthly income of respondents shows that $83(24.9 \%)$ earned less than 18,000 ,
168 (50.3\%) earned $18,000-47,000,55$ (16.5\%) earned ¥50, 000 - $100,000,16$ (4.8\%) earned 1100,000 - 150 , 000 and 12 (3.6\%) earned greater than 150,000 . This is as shown in Table 1 below.

\section{Prevalence of depression and anxiety among hyperten- sive's}

Depression and anxiety was determined using a standard tool known as depression, anxiety, and stress scale-21 (DASS21). Information on depression and anxiety were retrieved, scored and categorized. The Overall prevalence of depression and anxiety among the hypertensive patients was $77.8 \%$ (Figure 1). The result indicated that among the hypertensive's, $242(72.5 \%)$ had both conditions of depressed and anxious (comorbidity), 74 (22.2\%) were neither depressed nor anxious, $14(4.1 \%)$ were anxious but not depressed while $4(1.2 \%)$ were depressed but not anxious (Figure 2).

The result also indicated the depression and anxiety category of the participants. It revealed that 31 (9.3\%) had mild depression, 31 (9.3\%) had moderate depression, 59 (17.7\%) had severe depression while 73 (21.9\%) had extremely severe depression. Also 58 (17.4\%) had mild anxiety, $29(8.7 \%)$ had moderate anxiety, $57(17.1 \%)$ had severe anxiety while 112 (33.5\%) had extremely severe anxiety. This is shown in Table 2.

\begin{tabular}{|c|c|c|}
\hline Variables & Frequency (n=334) & Percentage (\% \\
\hline \multicolumn{3}{|l|}{ Age (years) } \\
\hline $20-29$ & 20 & 6.0 \\
\hline $30-39$ & 48 & 14.4 \\
\hline $40-49$ & 38 & 11.4 \\
\hline $50-59$ & 75 & 22.5 \\
\hline $60-69$ & 91 & 27.2 \\
\hline 70 \& above & 62 & 18.6 \\
\hline \multicolumn{3}{|l|}{ Sex } \\
\hline Male & 144 & 43.1 \\
\hline Female & 190 & 56.9 \\
\hline \multicolumn{3}{|l|}{ Marital Status } \\
\hline Single & 27 & 8.1 \\
\hline Married & 238 & 71.3 \\
\hline Widowed & 69 & 20.7 \\
\hline \multicolumn{3}{|l|}{ Education Level } \\
\hline non-formal & 33 & 9.9 \\
\hline Primary & 44 & 13.2 \\
\hline Secondary & 114 & 34.1 \\
\hline Tertiary & 143 & 42.8 \\
\hline \multicolumn{3}{|l|}{ Monthly Income } \\
\hline$<18,000$ & 83 & 24.9 \\
\hline $18,000-47,000$ & 168 & 50.3 \\
\hline $50,000-100,000$ & 55 & 16.5 \\
\hline $100,000-150,000$ & 16 & 4.8 \\
\hline$>150,000$ & 12 & 3.6 \\
\hline
\end{tabular}




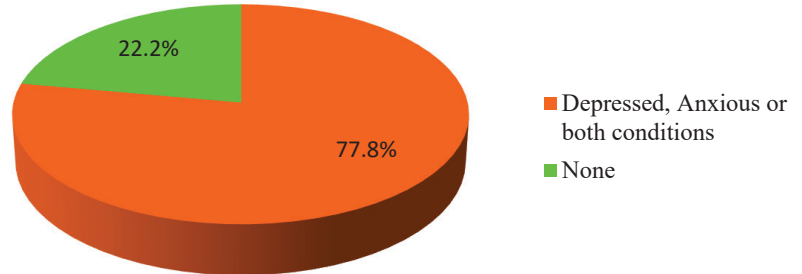

Figure 1: Overall prevalence of depression and anxiety among hypertensive Patients.

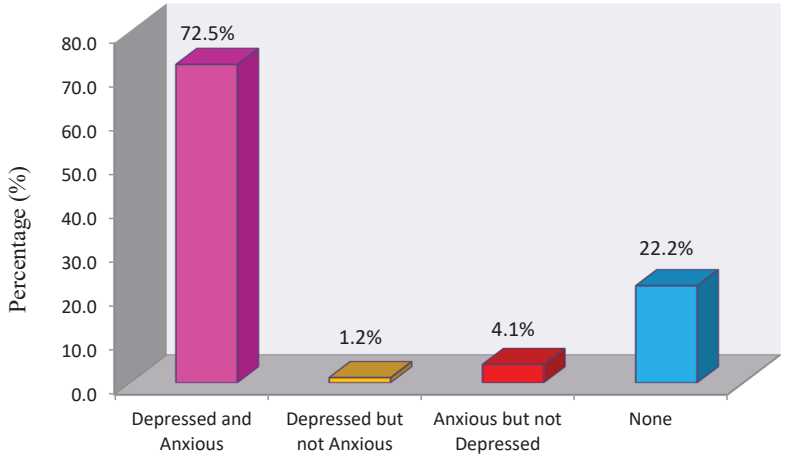

Figure 2: Depression and Anxiety Category of Respondents.

Table 2: Depression and anxiety category of hypertensive patients attending Imo Specialist Hospital.

\begin{tabular}{|c|c|c|}
\hline Variable & Frequency $(\mathbf{n = 3 3 4 )}$ & Percentage (\%) \\
\hline Depression category & & \\
Normal & 88 & 26.3 \\
Mild & 31 & 9.3 \\
Moderate & 83 & 24.9 \\
Severe & 59 & 17.7 \\
Extremely Severe & 73 & 21.9 \\
\hline Anxiety category & & \\
Normal & 78 & 23.4 \\
Mild & 58 & 17.4 \\
Moderate & 29 & 8.7 \\
Severe & 57 & 17.1 \\
Extremely Severe & 112 & 33.5 \\
\hline
\end{tabular}

\section{Discussion}

A higher percentage of the participants were aged above 60 years old. This could imply that the older a person becomes the higher the risk of hypertension. This finding is not different from the report of the study conducted in Urban Nepal by [10], which also reported a higher number of age group 45 to 64 years $169(53 \%)$ as respondents in their study. This is also inline with another study conducted in India which reported that $58 \%$ of their participants aged between $55-75$ years [11]. This is true because aging is associated with worry and worsening heath condition. This finding corresponds to that of Zhanzhan, et al. (2015) on the prevalence of depression among hypertensive [12]. Majority of the respondents in the present study were females $(56.9 \%)$. This is similar to the finding of Kulkarni \& Lingappa (2019) who reported $70 \%$ female participants. This also corresponds with another study by Norzila, et al. (2009) who carried out a study on The Effect of Depressive Disorders on Compliance among Hypertensive Patients [3]. Undergoing Pharmacotherapy which reported a higher number of females $104(51.7 \%)$ as respondents. Level of education shows that $143(42.8 \%)$ had tertiary education, $114(34.1 \%)$ had secondary education, 44(13.2\%) had primary education and 33(9.9\%) did have any formal education. This implies that greater proportion of the respondents had tertiary education. This may proves that most of the respondents had ample knowledge of their health conditions. This is contrary to the findings of Bernard, et al. (2014) and Sushil, et al. (2016) who reported a lower proportion of tertiary level of education among their respondents $[13,5]$.

The findings of this result indicated a high prevalence of $72.5 \%$ co-morbidity depression and anxiety among hypertensives. This finding is higher than $26.6 \%$ reported by Ademola, et al. (2019) [13], in a similar Nigeria hospital setting. It is also higher than $33.3 \%$ that reported by Prathibha, et al. (2017) amongst individuals in urban Trivandrum India [14]. In another study in Indian tertiary health care $40 \%$ prevalence of depression among hypertensives was reported [11]. A study in Kingdom of Saudi Arabia indicated that depression and/or anxiety was found in $57.3 \%$ of respondents with hypertension and diabetes [15]. This finding is also higher than $58.1 \%$ and 42.3\% prevalence reported comorbidity for depression and anxiety among hypertensives in Afghanistan City of Andkhoy [16]. The higher prevalence may be related to worries that come with having a chronic disease which includes financial burden, disability lost days, low socio-economic status, worsening condition and also lack of adequate care experienced in this part of the country. Hopelessness due to economic situation in this geopolitical region, where majority of the residents take home meager salary after putting in adequate manpower in their places of work could also exacerbate the situation. Also the difference could also arise from varying instrument used.

Furthermore severe depression and anxiety was found in $39.6 \%$ and $50.6 \%$ of the participants respectively. In a similar study conducted in another geopolitical zone in Nigeria severe depression was found in $2.9 \%$ of the hypertensives, while that of Ghana was $6.6 \%$ [13]. Nine percent severe depression was found in an Indian study [11], while $4.3 \%$ and $11.5 \%$ severity was reported for depression and anxiety in a study conducted in Saudi Arabia [15]. Also Severity of $4.0 \%$ was reported depression in a study conducted in Trivadrum India [14]. $5.5 \%$ was reported [17]. Just as explained earlier reasons for this could be geographical difference, difference in ethnicity and socioeconomic situation. Also poor hopelessness due to poor hypertensive control which could arise from influx of ineffective antihypertensive drugs in circulation.

\section{Conclusion}

There is a high prevalence of depression and anxiety among hypertensive patients. This is worrisome because depression and anxiety lower compliance to antihypertensive medication. Depression and Anxiety form a precipitating factor of hypertension, and hypertension can worsen symptoms of depression and anxiety. Therefore, combination of hypertensive medications with psychotherapy and antidepressants can definitely help prevent severe attacks of high BP. Hence this study underscores the need for psychiatric evaluation, 
counseling, and support services for hypertensives which will in-turn improve hypertension management in the society.

\section{Declarations}

\section{Ethics approval and consent to participate}

Permission to conduct the study was gotten from School of Health Ethical Committee, Federal University of Technology Owerri. Also a permission letter was gotten from the Chief Medical Directors Imo State Specialist Hospital. Verbal consent was obtained from the participants after all necessary explanations were given; this was deemed appropriate because of the general literacy level of the residents. During the data collection observations and information gotten were handled with utmost confidentiality.

\section{Availability of data and material}

The data used for this research was gotten from field survey conducted by the researchers and can be made available on Request.

\section{Authors' contributions}

CICE and UWD conceived the study, contributed in drafting the study and performed the statistical analysis.

MM, UE and AIO synthesized the analysis and interpreted findings.

EAO, EBO and CPE designed the questionnaire and also contributed in drafting of the manuscript.

ULI, QKD and UFA did the literature search and participated in data collection.

All authors participated in critical review of the manuscript and approved the final manuscript.

\section{References}

1. WHO (2011) Global Status Report of Non - Communicable Diseases 2010. Geneva: World Health Organization. Link: https://bit.ly/3i80LDB

2. James TA, Richard M, Aminu MU, Nick F (2015) Current Prevalence Pattern of Hypertension in Nigeria: A Systematic Review. PLoS One 10: e014002110. Link: https://bit.ly/3knwtPk

3. Norzila Z, Azlin B, Rosdinom R (2009) The Effect of Depressive Disorders on Compliance among Hpertensive Patients undergoing Pharmacotherapy. Asian Journal of Pschiatry 1-11. Link: https://bit.ly/2XqptXN
4. Vetere G, Ripaldi L, Ais E, Korob G, Kes M, et al. (2007) Prevalence of anxiety disorders in patients with essential hypertension. Vertex 18: 20-25. Link: https://bit.ly/2XtikWG

5. Sushil KS, Vineeta S (2016) Awareness, Stress, Anxiety, and Depression among Hypertensive Patients. Asian Journal of Pharmaceutical and Clinical Research 9: 62-64. Link: https://bit.ly/31okQ1X

6. Igwe MN, Uwakwe R, Ahanotu CA, Onyeama GM, Bakare MO, et al. (2013) Factors associated with depression and suicide among patients with hpertension. Afr Health Sci 13: 68-77. Link: https://bit.ly/31qRQ9Q

7. Aberha M, Gebeyehu A, Ayano G (2016) Prevalence and Factors Associated with Anxiety among Patients with Hypertension on Follow Up at MenelikII Referral Hospital, Addis Ababa Ethiopia. J Psychiatry 19: 4. Link: https://bit.ly/3fs99fl

8. Wolitzky-Taylor KB, Castriotta N, Lenze EJ, Stanley MA, Craske MG (2010) Anxiety disorders in older adults: a comprehensive review. Depress Anxiety 27: 190-211. Link: https://bit.ly/31duFPS

9. Kretchy IA, Owusu-Daaku FT, Danquah SA (2014) Mental health in hypertension: assessing symptoms of anxiety, depression and stress on anti-hypertensive medication adherence. Int J Ment Health Syst 8: 25. Link: https://bit.ly/3kglhDR

10. Dinesh N, Bindu P, Craig S (2015) Prevalence of Undiagnosed Depression among Persons with Hypertension and Associated Risk Factors: A CrossSectional Study in Urban Nepal. Plos One 10: 1371. Link: https://bit.ly/2PpoGCf

11. Kulkarni VG, Lingappa SH (2019) Prevalence of depression in patients attending general medicine outpatient department for hypertension. Int J Med Sci Public Health 8: 105-109. Link: https://bit.ly/2Xu0pPK

12. Zhanzhan L, Yanyan L, Lizhang C (2015) Prevalence of Depression in Patients With Hypertension. A Systematic Review and Meta-Analysis. Medicine 94: e1317. Link: https://bit.ly/39ValBD

13. Ademola AD, Boima V, Odusola AO, Agyekum F, Nwafor CE, et al. (2019) Prevalence and determinants of depression among patients with hypertension: A cross-sectional comparison study in Ghana and Nigeria. Niger J Clin Pract 22: 558-565. Link: https://bit.ly/33tB2B|

14. Prathibha MT, Varghese S, Dev GV, Jincy J (2017) Prevalence of depression among hypertensive individuals in urban Trivandrum: a cross sectional study. Int J Community Med Public Health 4: 2156-2161. Link: https://bit.ly/3kkA3tB

15. Alkhathami AD, Alamin MA, Algahtani AM, Alsaeed WY, Alkhathami MA, et al. (2017) Depression and anxiety among hypertensive and diabetic primary health care patients. Saudi Med J 38: 621-628. Link: https://bit.ly/2DohJir

16. Hamrah MS, Harmrak MH, Ishii H, Suzuki S, Harmrah MH, et al. (2018) Anxiety and Depression among Hypertensive Outpatients in Afghanistan: A CrossSectional Study in Andkhoy City. International Journal of Hypertension 2018: 8560835. Link: https://bit.ly/2DkZpGW

17. Ashok VG, Ghosh SS (2019) Prevalence of Depression among Hypertensive Pa- tients Attending a Rural Health Centre in Kanyakumari. Nat J Community Med 10: 172-175. Link: https://bit.ly/3keOxLq

Copyright: @ 2020 Casmir Ebirim Cl, et al. This is an open-access article distributed under the terms of the Creative Commons Attribution License, which permits unrestricted use, distribution, and reproduction in any medium, provided the original author and source are credited. 